\section{An anthropologic study on strategies for addressing health problems among the elderly in Bambuí, Minas Gerais State, Brazil}

\author{
Um estudo antropológico sobre as estratégias \\ para resolver problemas de saúde entre idosos \\ de Bambuí, Minas Gerais, Brasil
}

\author{
Elizabeth Uchôa 1 \\ Josélia O. A. Firmo 1 \\ Maria Fernanda Lima-Costa 1 \\ Ellen Corin 2
}

\title{
Introduction
}

1 Núcleo de Estudos

em Saúde Pública

Envelhecimento, Fundação Oswaldo Cruz/Universidade Federal de Minas Gerais, Belo Horizonte, Brasil.

2 Douglas Mental Health

University Institute, McGill

University, Québec, Canada.

Correspondence

J. O. A. Firmo

Núcleo de Estudos em Saúde

Pública e Envelhecimento,

Fundação Oswaldo Cruzl

Universidade Federal de Minas

Gerais.

Av. Augusto de Lima 1715,

6 o andar, Belo Horizonte, $M G$

30190-002, Brasil.

firmoj@cpqrr.fiocruz.br

\begin{abstract}
This paper explores the contribution of anthropo-
Abstract

logical perspectives for clarifying the mechanisms through which socioeconomic circumstances influence the strategies developed by elderly for addressing their health problems in a small Brazilian city. Interviews with $20 \mathrm{key}$-informants explored the community's broad perception of the health situation of the elderly. Life histories collected from 30 elderly women examined their own perception of their health status and their health strategies. Narratives converge in emphasising the important role played by financial factors in accessing health services and medication. Life histories also describe some damaging strategies resorted to by the elderly to deal with their lack of resources. Elderly women emphasize the crucial support they receive from their family and/or neighbours to overcome health problems. Thus, the issue of poverty is not only a matter of socioeconomic circumstances, but also the poverty of broader social networks.
\end{abstract}

Socioeconomic Factors; Anthropology; Health of the Elderly; Cohort Studies
Socioeconomic circumstances play a central role in determining the health of individuals and populations. Reducing health inequities is an ethical imperative worldwide 1 . As health-care systems are a vital determinant of health, they should be designed and financed in such a way as to ensure equitable, universal coverage with adequate human resources. This has been recently recommended by the Commission on Social Determinants of Health 1 . And with the aging of the population, health-care systems must be focused on supporting healthy aging 1 .

Two decades ago, Brazil aimed to achieve universal health-care coverage by launching the Brazilian Unified National Health System (SUS). The SUS is the source of health care for approximately two thirds of the elderly Brazilian population 2 . Among users of SUS, the per capita household income is three and a half times lower than what is observed among the elderly with coverage from a private health insurance plan 2 .

Social inequalities in health among the Brazilian elderly are striking. A nationally representative health survey showed that compared with the better off, those in the lowest quintile for monthly household income present worse health status and worse physical functioning. In spite of that, they use less medical services 3 , suggesting a situation that has been described as the inverse care law 4 Another population-based epidemiological study, 
conducted in a small Brazilian city, showed that even small differences in family income are sufficient to produce inequalities in health and healthrelated conditions. Monthly family income in the lowest tertile $(<240.00$ USD) was associated with unhealthy lifestyle, worse mental and physical health, worse functioning, greater use of non-prescribed medications, and higher hospitalizations rates 5 . However, the mechanisms through which socioeconomic factors influence health, particularly health services and medication use, are not fully understood.

The main objective of this anthropologically inspired study was to examine some of the mechanisms through which socioeconomic circumstances influence the strategies for addressing health problems among the elderly, with an emphasis on the use of health services and medication among those living in the above mentioned small city in Brazil.

\section{Methodology}

\section{Study area}

A population based cohort study of ageing has been conducted in Bambuí city ( 15,000 inhabitants), located in Minas Gerais State, Southeastern Brazil since mid-1990. The Human Development Index in the study area is 0.70 and life expectancy at birth is 70.2 years. Low income and low schooling levels predominate among the city's elderly inhabitants: $73 \%$ earn less than USD 280 per month, and $65 \%$ have less than four years of schooling. At the cohort baseline, the health profile of the older residents revealed a double burden of disease, that is high prevalence of chronic nontransmissible diseases and Chagas disease (which is caused by the protozoan Trypanosoma cruzi). This infection in old age is a consequence of early exposure to a triatomine bug that colonizes poor households. The prevalence of cardiovascular risk factors and diseases (such as hypertension, diabetes mellitus, stroke, intermittent claudication, and smoking) was similar to those observed in other elderly populations worldwide. The prevalence of mental symptoms (such as common mental disorders, depression and insomnia) was also similar - or even higher. Further details of this study are described elsewhere 6,7.

With regards to health services, Bambuí has one general hospital with 62 beds, 15 physicians ( 1 per 1,000 inhabitants) and a public polyclinic providing 24 hour access to urgent care. Some medications are distributed free by the public health system. More recently, the Family Health Strategy was launched in the study area. Among inhabitants aged 60 and over, $80.7 \%$ were under exclusive SUS coverage and $19 \%$ had a private health insurance plan 6,7 .

\section{Theoretical framework}

In the present study ageing was approached as a universal phenomenon that generates problems which are common but can be lived through and resolved in different ways depending on personal, social and cultural factors 8 . From that perspective, ageing is not a state to which individuals are passively submitted. It is a biological phenomenon to which people react on the basis of personal and cultural references 9,10,11. This meets the way medical anthropology approaches the notions of health and disease. Whatever their biological basis, diseases are embedded within webs of meanings that are constructed at individual, social and cultural levels and that influence the way to react to health problems.

Regarding health care utilization, it is now well recognized that the availability of services is not sufficient for ensuring that they are used and several models have been proposed for explaining that discrepancy 12. Several authors have emphasized the necessity to complement available epidemiological data by more intensive, qualitative studies $13,14,15,16$. Within that context, medical anthropology proposes that health seeking pathways have to be understood within the context of broader representations of health and disease, of explanatory models, available social support and of the characteristics of the health care system $17,18,19$. This perspective has been operationalized by Corin et al. 20 in the area of mental health through the "signs, meaning, and practices model”. In a study comparing perceptions and reactions across six communities in order to explore the influence of cultural and socio-historical factors, mental health and mental health problems were studied at the level of their perceived manifestations, interpretations and the practices developed in order to deal with them.

We have built on these various approaches with the aim of better understanding the ways in which the elderly deal with their health problems. We paid particular attention to their representation of aging, and to their perceptions, values and behaviours regarding the health seeking process, as well as to the constraints that they face when interacting with the health care system.

\section{Data collection}

Two methods of data collection were used: keyinformant interviews and the reconstruction of 
life stories with elderly women. The study with key informants aimed at obtaining a general picture of the situation as perceived by the community. The life histories of elderly persons aimed to show how health problems and strategies were concretely embodied in the context of their daily lives. Both sets of interviews focused on the strategies for addressing health problems in old age. Interviews with key informants focused on the kind of contacts they have with people over the age of 60 , on the perceived life conditions of the elderly, and on the particular opportunities and difficulties encountered by the elderly. Life histories explored in a very open way the general flux of these women's lives, aging and their current situations; they also touched upon significant events and ways to deal with them, the main problems faced at this stage of their lives and their strategies for dealing with them, their perceptions of others' attitudes and behaviours towards them. If necessary, more specific questions were also asked regarding health issues.

The selection of participants did not aim at representativeness but at getting the perspectives from persons who had a good knowledge of their milieu. 20 key-informants (10 individuals aged $\geq 60$ and 10 individuals aged between 35 and 59) were identified among community members. From these, four were volunteers in charity work, five were active members of their churches, five were members of community associations (such as Lions Club, Rotary Club and the local elderly people's association), three were health workers, and three were civil servants involved in pensions, education and social work, respectively.

The other group consisted of 30 elderly women (aged $\geq 60$ ), selected on the basis of their participation in the community. From these, 13 were between 60 and 69 years old, 12 between 70 and 80 years old, four were between 80 and 89 years and one was over 90 . The majority of them were widows with children and a low level of schooling. 10 had never had children, five had never been married and only one had a graduate degree. 12 said they lived on a pension equivalent to one Brazilian minimum wage per month (about US\$120), twelve claimed to have property and to have no financial problems, and the remaining were in between these two extremes.

Interviews with key-informants (KI) were carried out by one of the authors (E.U.) and the reconstruction of life histories by a lady aged 68 years, leader of an elderly people's association in Belo Horizonte, Minas Gerais State, Brazil.

\section{Data analysis}

Data analysis was based on the model of signs, meanings and practices aimed at describing and comparing perceptions, interpretations and actions across several communities, and at exploring the role of culture and macro-social conditions 21. At the methodological level, this approach reverses the usual orientation of studies on representations of health and disease. The analysis begins with the pragmatic level of actions and reactions and then evolves towards the semantic level of signs and meanings. It promotes a dialogue between the particularity of conducts related to health and the generality of the biomedical model, enlightening the cultural logics that explain convergences and discrepancies 22 . The model seeks to describe the ways of thinking and acting of people; it identifies the categories through which different subgroups of people recognize, explain and respond to health problems, how they rely on an implicit system of signs (of illness), meanings (attributed to the experience of illness) and practices (care). It gives access to the conceptual logic privileged by a population for understanding specific health problems, and identifies the elements underlying the behaviors through which a particular population approaches a particular problem 22 .

All the interviews were taped and transcribed. A careful reading of the interviews allowed us to identify meaningful units and to create analytical categories 21,22 . The code was tested in further interviews and revised to be sure that all the relevant information could be coded according to these categories, with a minimum of ambiguity. The Qualittat software 23 (Centro de Pesquisas René Rachou, Fundação Oswaldo Cruz, Belo Horizonte, Brazil) was used in order to mark the text according to the categories defined by that procedure. We extracted the excerpts corresponding to a particular category of information and used these excerpts in order to specify further the description of the categories and to grasp the nuances of responses according to the participants. Finally the interactions between the different categories of information were analysed. In the present study, questions related to health were the central axis of the analysis. We selected all references to health problems, the strategies developed to resolve them and the difficulties encountered in this process. Both sets of interviews were analyzed separately and compared.

The study was approved by the Ethics Research Committee of the René Rachou Research Center of the Oswaldo Cruz Foundation (Centro de Pesquisas René Rachou, Fundação Oswaldo 
Cruz), Belo Horizonte, Brazil. All names are fictitious.

\section{Results}

\section{Key-informant interviews}

As a whole, in the interviews with KI, old age and the ageing process were associated with distinct levels of health problems. Informants referred to the appearance of chronic illnesses, the constant use of medication and the increased need to visit medical services. The old person is "constantly ill" (KI5). "Because of age, an elderly person needs more medication and help, he/she is like an old machine. An old machine doesn't work as well as a new one, and this is natural" (KI12), explains another informant. According to informants what makes the situation more complicated is the combination of increased health needs and difficulties in accessing medical care and medication. One informant explains that "in general, people understand that health can only be assured if one has money" (KI1). This idea is reinforced by the informant's explanation regarding the need to pay for medical consultation: "If you're ill, you seek out a doctor. You have to pay" (KI21). Another informant confirms this, saying that "a very poor person shows up for an appointment [in the public sector] and they have the nerve to ask him to pay a quarter of the consultation price" (KI12). In this context, user's purchasing power is identified as a determinant factor for his/her access to health services. Lack of information is identified as another aggravating factor. Two informants said that many people do not know where to go, or which service to look for and, even more importantly, do not know that free medical care is a universal right in this country. This situation is illustrated by the case of a lady who "had erysipelas on her leg and wore long pants to hide the lesions; she thought that there was no medicine or even the need to go to a doctor". For some time, this lady coped with this problem only by "drinking some herbal teas" (KI6).

Another important source of difficulties identified by informants was the way in which medical care is organised: "You have to pick up a consultation card, you have to put up with standing in line, it's not easy at all, no" affirms one informant (KI5); sometimes it is necessary "to even sleep in the square to make sure of getting an appointment card", adds another (KI9). The appointment card is the normal procedure used to manage the distribution of medical appointments in the public sector in Bambuí. Even so, some informants emphasise that age is an important obstacle to getting an appointment when one needs to face long lines for many hours "a 70 year old person has difficulty in picking up a consultation card" (KI9). Those unable have to pay someone to pick up a consultation card for them. This confirms once again that "those with money have more access to medical services" (KI1). One informant suggests that "the elderly person needs a suitable way to get health assistance; just as he [or she] has a free bus pass, he [or she] needs a different way of getting medical care" (KI10).

In addition to the difficulties encountered in making an appointment or receiving free medical care, informants also point out that the elderly person often needs to be accompanied or even transported to the health care centre. The role of families in this context is perceived as fundamental: "some people die for lack of help. The family doesn't care; they don't bother to help" (KI21). In cases where it is not possible to count on the help of families, this role is carried out by community or religious organisations. Representatives of these associations explain: "people from the church get the patients, take them to the doctor, wait during the appointment and take them back home" (KI15); "if they are ill we send them to the doctor, we take them to the hospital and we give them medication" (KI22).

Visiting the drugstore and consulting the pharmacist is an alternative strategy that the elderly frequently adopt when a medical consultation is seen as impossible. One informant explains that when they are unable to get a medical appointment "people go the drugstore where the pharmacist gives his opinion based on his experience" (KI12). Another person adds "people buy the medicines they are accustomed with and ask the pharmacist if they can continue to use it and what is the dose" (KI5).

Obtaining prescribed medication is identified by the informants as another source of difficulties: "sometimes one can get an appointment, but one still has problems because our health service doesn't have medicines" (KI9). In some interviews the role of a pension in buying these drugs is emphasised: "pension money at least pays for medicines" says one informant (KI22). In the majority of the interviews there is some reference to the fact that "all old people take lots of medication" and several informants believe that "spending with drugs and treatments" leads to a considerable worsening of the economic situation. One of them comments that often an old person spends up to "the last cent that he or she has to buy food, milk, things like that" (KI12) on medication. Another informant explains that the partial acquisition of prescribed medication is a strategy frequently used by old people to confront the situation 
created by the combination of the high cost of drugs and the low income of this population: "when you [the elderly] have to buy medicines you buy just a little. It's like when you owe a bill and you don't have money to pay it all, you pay just a little" (KI5). Reducing the prescribed dose appears to be another strategy also used by elderly people: "if we don't keep an eye on her, she doesn't take her medication. She was told to take three pills a day, but she takes only two. When money is tight, when she is broken, she takes one. Then, the heart beats faster and she has problems with blood pressure" (KI7). All these interviews reinforce the idea that access to medication is profoundly influenced by the user's purchasing power.

\section{Life stories of elderly women}

Dona Joaquina is an old lady aged 94, who has been bedridden for the last few months. She broke one leg and two months later broke the other, but surprisingly defines her health as being "very good". Dona Maria is 80 years old and says she always had back problems and suffers from osteoarthritis, “but nothing serious, I've never had any fracture and I only take medication to strengthen the heart". Dona Norma says that her problem is with her heart: "I was bitten by a triatomine bug and for the past few years I've had dryness in the mouth, but I work, do the laundry and ironing, walk a lot, eat well, sleep all night and don't worry about the future...". Dona Ana is 60 years old and says she has angina and has already undergone angioplasty, but affirms that she is in good health because she is obedient and wants to "live longer". Health problems appear in almost all the reports. However, the severity and the relevance of problems are clearly determined by the possibility of confronting these, whatever the problems may be.

For the great majority of interviewees, the family, and particularly sons and daughters, is the main source of support. In moments of ill health the family plays a fundamental role. In general, children take care of their parents, oversee treatments, make the relevant decisions, make medical appointments and pay the bills. Dona Joaquina is very well cared for by her daughters and says that when she needs a doctor "it's always private". Dona Judite says that she has diabetes and that this is her main health problem. She has no medical insurance, but thanks to her sons and daughters she can go to a private cardiologist, endocrinologist and gerontologist in Belo Horizonte (the State capital which concentrates the most advanced medical services): "my sons make a collection and all of them put in a little money". Dona Marta says that she always went to a private physician, but that now she has medical insurance as a dependent of her son. Dona Regina says she has undergone several surgeries (appendicitis, uterus, ovary) and always received private medical care, explaining "when my husband was alive it was always he who paid, nowadays if I need help I ask my sons". It is interesting to note that health does not seem to be a problem for any of these ladies, despite the problems that each of them reports (diabetes, Chagas' disease, fractures, cardiac problems). It should be emphasised that even when women have high purchasing power, almost all of them seek help from their sons to cope with the necessary health expenses.

The support of one's son is, almost always, viewed as unconditional "my sons are poor, but if I need help, I know they'll provide it" says Dona Dulce. In rare cases, and always in the absence of sons and/or daughters, more distant relatives, neighbours, friends or even acquaintances may play a preponderant role. This is the case for Dona Ana who is single and has no son: "I can't count on the help of my brothers and sisters, not financially, even emotionally. Among my family members I can only count on a nephew, but my neighbours are marvellous". Dona Dalmar is a widow and did not have children; however, she receives great support from her sister: "it's my sister who makes the appointment with the doctor and doesn't let me pay. She has a very good pension from her husband. Her sons and daughters are also very good to me, actually our family is very close". Dona Eneida explains that she has two nephews who work in the health service, so that when she needs to see a doctor "I only have to ask and they make the appointment".

Dona Áurea had received hospital treatment under the public system, but she needed to pay someone to pick up the consultation card for her: "They charge R\$ 5 or 10 [about US\$ 5 or US\$ 10 at this time]". Dona Jane uses the same strategy to make her medical appointments: "I get my consultation card at the city hall, one has to go there very early. Before I used to stay in line, now I pay somebody to pick up the card for me". Dona Nédia says that she also pays someone to pick up the card for her, but when she needs and cannot get one, then she pays "half of the consultation price". Payment for medical appointment, often at a quarter, third or half of the regular price, is another strategy developed to avoid the long lines to obtain a consultation card. The choice of private treatment may also be a function of dissatisfaction with free medical attention. Dona Elza says that she prefers to "make the sacrifice" and pay to receive better care. Dona Augusta agrees and says that, in ad- 
dition to the difficulty of picking up an appointment card and the long wait in the health service, the free (public) attendance is "very fast" and of poor quality.

Dona Jane explains that, being diabetic, she has to have regular check-ups; however, twice she went to the health service and as the equipment was broken, she ended up paying a laboratory $\mathrm{R} \$$ 12 (about US\$ 12). After this, she spent two years without being examined "and my diabetes went to 330 ". To be able to buy prescribed drugs is also seen as essential to well-being. The economic situation of the elderly and of their family is thus one of the fundamental factors for maintaining health. In this context, the pension, small as it is, plays a role of major importance: "I don't have problems because of my pension, which is enough to buy food and medicines" says Dona Marta. For Dona Lourdes, the benefit of the pension is a real blessing from heaven "sacred money, are you kidding? If I want to buy candy, I buy it. If I want to buy milk, I do", but it remains insufficient to afford the medication: "I get by as far as my normal needs go, but buying medicine, now that's another story, isn't it?". For Dona Nedina, the pension is enough to buy drugs, but "it's my daughter who puts food on the table".

For those without a fixed income, the solidarity of the community is essential: "I barely live within my means because I have diabetes and high blood pressure and I can't do without the medication that I have to take. People help me. Sometimes someone leaves some medicine, another leaves a basket of food" explains Dona Nenen. Dona Jandira also needs to count on the goodwill of the doctor "who attends free of charge and even gets me the exams and drugs".

\section{Conclusions}

The comparison between KI interviews and life histories indicates that they approach issues related to the health status of the elderly in slightly different ways. KI focused particularly on factors related to health services, while elderly people were rather stressing their more global strategies for addressing their health problems. KI tended to see elderly health problems from the perspective of their difficulties to access medical care and medication. The elderly, on the other hand, disclosed a great diversity of realities and experiences. Although the old ladies confirmed the presence of difficulties and health problems, they were also careful to minimize their importance, or rather, to maintain a positive image of themselves, so that they did not dwell on their health problems.
For both KI and old ladies, the financial situation was an important part of the picture. Despite the universal nature of the public health system in Brazil, paying the medical consultation price arose as a problem in many discourses. In these cases, paying a half, a third or even a quarter of the doctor's consultation was a frequent strategy. For those using the public health system, the most important difficulty seemed to be queuing sometimes for long hours to make a medical appointment.

An additional problem was to get the prescribed medicines. When the public system did not have the medication to deliver free of charge, the old ladies needed to buy it. Often, the prices of these drugs were far beyond their affording condition. Actually, financial problems were often highlighted as the main difficulty in obtaining medication for the poor ladies. In order to face this problem, they tended to adopt strategies that could have a negative effect on their health, such as buying only a part of the prescribed medicines or reducing the dosage.

Finally, when explaining their ways of dealing with the above mentioned problems, the old ladies mentioned primarily their reliance on their informal social support networks; resorting to health services seemed second in importance in their narratives: primarily children, but when they are not accessible, relatives and even neighbours; and in case of a lack of social resources, they paid somebody. The solidarity of the community was an essential ingredient of elderly women's health. This suggests that "poverty" cannot be reduced to a matter of socioeconomic circumstances; it may also represent a shortage of broader social resources that significantly aggravates its impact and should be included in a broad notion of "poverty".

Very few qualitative studies have been conducted on the factors that may influence health problems from the perspective of the elderly themselves. We are aware of none of them in Brazil. One study specifically dealing with vulnerable elderly 24 points to the constraining role of social isolation, care burden for the entourage, low mood and broad factors related to health care organization. Studies with other populations have also emphasized a range of factors from those related to the organization and accessibility of health services to experience of satisfaction and dissatisfaction with health care and cultural beliefs. Most insist on the necessity to develop culturally sensitive outreach programs.

Our study allows one to grasp better the normative frame and the community values that underlie the factors evidenced in other studies and to specify them in reference to the specific 
context of Bambuí. It also identifies the resources available in the milieu and suggests that it may be interesting to broaden common perspectives on health care and to rethink its organization in the case of elderly, such as to include more partnership with natural support systems. The notion of complementarity would be important in that context, as would the idea of supporting carers in their helping role. It may also be important to support elderly in their effort to maintain a positive vision of themselves amidst their difficulties and help them mobilize their personal resources for health. More generally, results also allow for more precise targeting of the way constraints associated with poverty translate in the helpseeking process and to elaborate specific ways to respond to these.

\section{Resumo}

Este artigo utiliza a abordagem antropológica para examinar mecanismos por meio dos quais a situação socioeconômica influencia as estratégias desenvolvidas por idosos residentes em uma pequena cidade brasileira para enfrentar seus problemas de saúde. Entrevistas com vinte informantes-chave visaram à percepção da comunidade acerca da saúde do idoso. Entrevistas com trinta senhoras idosas objetivaram a percepção que elas possuíam da saúde e estratégias adotadas para resolver tais problemas. As análises mostraram que as narrativas dos dois grupos convergem na ênfase do papel desempenhado por fatores financeiros no acesso aos serviços de saúde e aos medicamentos. As histórias de vida descreveram algumas estratégias prejudiciais à saúde para fazer frente à falta de recursos. As senhoras também destacaram a importância do apoio da família elou de vizinhos para superar problemas relacionados à saúde. Assim, a questão da pobreza não é só econômica, mas também a pobreza das redes sociais de apoio.

Fatores Socioeconômicos; Antropologia; Saúde do Idoso; Estudos de Coortes

\section{Contributors}

E. Uchôa conceived the project, participated in the data analysis and interpretation, wrote up the article and approved the final version. J. O. A. Firmo and E. Corin participated in the data analysis and interpretation, critical review of the article and approval of the final version. M. F. Lima-Costa collaborated in the project design, critical revision of the article and approval of the final version.

\section{Acknowledgments}

To CNPq and FAPEMIG for their financial support. 
1. Commission on Social Determinants of Health. Closing the gap in a generation: health equity through action on the social determinants of health. Final Report of the Commission on Social Determinants of Health. Geneva: World Health Organization; 2008.

2. Lima-Costa MF, Matos DL. Tendências das condições de saúde e uso de serviços de saúde da população idosa brasileira: 20 anos de Sistema Único de Saúde. In: Departamento de Análise de Situação de Saúde, Secretaria de Vigilância em Saúde, Ministério da Saúde, organizadores. Saúde Brasil 2008: 20 anos de Sistema Único de Saúde (SUS) no Brasil. Brasília: Ministério da Saúde; 2009. p. 385-406.

3. Lima-Costa MF, Matos DL, Camarano AA. Evolução das desigualdades sociais entre idosos e adultos brasileiros: um estudo baseado na Pesquisa Nacional por Amostras de Domicílio (PNAD, 1998, 2003). Ciênc Saúde Coletiva 2006; 11:941-50.

4. Hart JT. The inverse care law. Lancet 1971; 1:405-12.

5. Lima-Costa MF, Barreto SM, Uchôa E, Firmo JOA, Vidigal PG, Guerra HL. The Bambuí Health and Aging Study (BHAS): prevalence of risk factors and use of preventive health care services. Rev Panam Salud Pública 2001; 9:219-27.

6. Lima-Costa MF, Firmo JOA, Uchôa E. Cohort profile: the Bambuí (Brazil) Cohort Study of Aging. Int J Epidemiol 2010; [Epub ahead of print].

7. Lima-Costa MF, Firmo JOA, Uchôa E. The Bambuí Cohort Study of Aging: methodology and health profile of participants at baseline. Cad Saúde Pública 2011; 27 Suppl 3:S327-35.

8. Meyerhoff B, Simic A. Life's career aging: cultural variations on growing old. London: Sage Publications; 1978.

9. Corin E. Regards anthropologiques sur la veillesse. Anthropol Soc 1982; 6:63-90.

10. Marshall V. A sociological perspective on aging and dying. In: Marshall V, editor. Later life: the social psychology of aging. California: Sage Publications; 1986. p. 304-36.

11. Marshall V. Social perspectives on aging: theoretical notes. In: Marshall V, editor. Aging in Canada: social perspectives. Markham: Fitzhenry \& Whiteside; 1987. p. 489-504.

12. Andersen RM. Revisiting the behavioural model and access to medical care: Does it matter? J Health Soc Behav 1995; 36:1-10.

13. Butler C, Kim-Godwin Y, Fox JA. Exploration of health care concerns of Hispanic women in a rural: Southeastern North Carolina community. Online J Rural Nurs Health Care 2008; 8:22-32.
14. Cristancho S, Garces DM, Peters KE, Mueller BC. Listening to rural Hispanic immigrants in the Midwest: a community based participatory assessment of major barriers to health care access and use. Qual Health Res 2008; 18:633-46.

15. Goldstein AE, Safarik L, Reiboldt W, Albright LA, Kellett C. An ethnographic approach to understanding service use among ethnographically diverse low income families. In: Gilgun JF, Susman MB, editors. The methods and methodologies of qualitative family research. New York: Haworth Press Inc.; 1996. p. 297-321.

16. Simkhada B, Teijlingen ER, Porter M, Simkhada P. Factors affecting the utilization of antenatal care in developing countries: systematic review of the literature. J Adv Nurs 2008; 61:244-60.

17. Kleinman A. Patients and healers in the context of culture. Berkeley: University of California Press; 1980.

18. Good BJ, Delvechio Good M-J. The meaning of symptoms: a cultural hermeneutic model for clinical practice. In: Eisenberg L, Kleinman A, editors. The relevance of social sciences for medicine. Dordrecht: D. Reidel Publishing Company; 1981. p. 165-96.

19. McKinlay J. Social networks, lay consultation and help-seeking behaviour. Soc Forces 1973; 51:27585.

20. Corin E, Bibeau G, Martin J-C, Laplante R. Comprendre pour soigner autrement. Repères pour régionaliser les services de santé mentale. Montréal: Presses de l'Université de Montréal; 1990.

21. Corin E, Uchôa E, Biebeau G, Koumare B, Coulibaly B, Sissoko M, et al. La place de la culture dans la psychiatrie africaine d'aujourd'hui: paramètres pour un cadre de références. Psychopathologie Africaine 1992; 24:149-81.

22. Uchôa E, Vidal JM. Antropologia médica: elementos conceituais e metodológicos para uma abordagem da saúde e da doença. Cad Saúde Pública 1994; 10:497-504.

23. Demicheli WA, Uchôa E. Qualittat: um programa de análise qualitativa para micro-computadores. Versão 2.0. Belo Horizonte: Centro de Pesquisas René Rachou, Fundação Oswaldo Cruz; 1997.

24. Nelms L, Johnson V, Teshuva K, Foreman P, Stanley J. Social and health actor affecting community service use by vulnerable older people. Australian Social Work 2009; 62:507-24

Submitted on $04 /$ Oct $/ 2010$

Final version resubmitted on $03 / \mathrm{Feb} / 2011$

Approved on 21/Feb/2011 